\title{
Migração, pesquisa biográfica e emancipação social: Contributo para a análise dos impactos da pesquisa biográfica junto de migrantes
}

Migration, Biographical Research and Social Emancipation: Towards an Analysis of the Impact of Biographical Research with Migrants Migration, recherche biographique et émancipation sociale: Contribution à l'analyse des impacts de la recherche biographique près de migrants

\section{Elsa Lechner}

\section{OpenEdition}

\section{Journals}

Edição electrónica

URL: http://journals.openedition.org/rccs/336

DOI: $10.4000 /$ rccs.336

ISSN: 2182-7435

\section{Editora}

Centro de Estudos Sociais da Universidade de Coimbra

Edição impressa

Data de publição: 1 Junho 2009

Paginação: 43-64

ISSN: 0254-1106

Refêrencia eletrónica

Elsa Lechner, « Migração, pesquisa biográfica e emancipação social: Contributo para a análise dos impactos da pesquisa biográfica junto de migrantes », Revista Crítica de Ciências Sociais [Online], 85 | 2009, colocado online no dia 01 dezembro 2012, criado a 23 abril 2019. URL : http:// journals.openedition.org/rccs/336 ; DOI : 10.4000/rccs.336 


\section{Migração, pesquisa biográfica e emancipação social: Contributo para a análise dos impactos da pesquisa biográfica junto de migrantes}

O presente artigo debruça-se sobre o impacto pessoal e colectivo de práticas de biografização junto de migrantes. Partindo de uma investigação em antropologia sobre processos identitários em situação de imigração (portugueses em França), sobre sofrimento e resiliência de migrantes pacientes de uma consulta de psiquiatria cultural (Portugal), e com base na experiência de trabalho biográfico em grupo (UNEB, Brasil), trata-se de apresentar os efeitos formadores, transformadores e emancipatórios das práticas de biografização. O texto providencia uma reflexão teórica, metodológica e sociopolítica acerca do trabalho biográfico junto de populações migrantes. Para além da análise dos efeitos produzidos pela pesquisa biográfica, também é aqui proposta uma aproximação consciente entre investigadores e profanos, no horizonte de uma epistemologia cívica, ou seja, da co-produção de saberes e da construção de coesão social.

Palavras-chave: migração, pesquisa biográfica, práticas de emancipação social, relações interculturais, epistemologias cívicas.

\section{Introdução}

O presente artigo visa apresentar um quadro de reflexão sobre os efeitos emancipatórios verificados no exercício de biografização de migrantes de várias origens em diferentes contextos e terrenos de análise. A biografização consistiu, nestes casos concretos, na produção de relatos biográficos feita pelos migrantes sobre as suas experiências de migração. Verificámos na prática de entrevistas e ateliês biográficos que tais narrativas (orais e escritas) têm um alcance emancipatório baseado em três aspectos principais: a validação dos testemunhos privados para além da etiquetagem ou superfície de discurso; a valorização das experiências dos migrantes frequentemente anuladas por estereótipos e estigmatizações sociais; a co-construção de um novo saber que reconhece, em pé de igualdade, a experiência e sua elaboração teórica. 
Este triplo alcance leva-nos a reflectir sobre a responsabilidade ética e política da abordagem biográfica, uma vez que esta contribui para transformar a percepção de si por parte dos actores sociais, bem como encontrar autonomamente poderes de decisão e novas formas de participação social. A pesquisa biográfica reveste-se assim de uma pertinência pessoal e colectiva que não só pode concorrer para o diálogo intercultural e para a construção da coesão social, como pode estabelecer ligações entre diferentes formas de produção de saber: o saber dominante dos académicos que somos nós próprios, e os saberes experienciais dos sujeitos no terreno. Nos contextos de diversidade como são os de e/imigração, tais efeitos requerem uma análise crítica que vá mais além da mera observação distanciada dos "objectos", reconhecendo-lhes a sua dimensão de sujeitos comummente negada até por cientistas sociais dedicados ao estudo das migrações.

Porque existem correntes autónomas das ciências sociais e humanas que fazem investigação biográfica na área da emancipação social, situaremos primeiro a nossa análise num breve resumo sobre o conceito de emancipação e sobre o âmbito científico das chamadas "práticas emancipatórias". Descreveremos depois a nossa experiência de pesquisa biográfica no terreno das migrações. Mostraremos seguidamente o modelo analítico do processo de biografização com as suas implicações teóricas e metodológicas. Finalizaremos pelas perspectivas éticas e sociopolíticas do desenvolvimento das práticas emancipatórias junto de migrantes, comparáveis a medidas que podemos apelidar de capacitação voluntária.

Há que deixar claro desde o início que a nossa análise repudia qualquer conotação paternalista ou de "domesticação" dos migrantes. Trata-se aqui de assumir o impacto da abordagem biográfica junto de pessoas que aceitaram falar das suas vidas no contexto de dois projectos de investigação antropológica: um sobre migração, identidade e memória (junto de emigrantes portugueses em França), outro sobre sofrimento e resiliência com utentes da "Consulta do Migrante" em funcionamento no hospital Miguel Bombarda de Julho de 2004 a Dezembro de 2007. Uma experiência de ateliê biográfico realizada com os alunos de Mestrado em Educação e Contemporaneidade da UNEB (Abril de 2006) permite aqui ainda fazer a ponte para a prática de um dispositivo biográfico junto de migrantes eventualmente interessados nesse exercício.

Consideramos que esta proposta tem a pertinência de pensar os exercícios de biografização dos migrantes como espaços de visibilidade e legitimação dos seus testemunhos. Estes têm um interesse tanto individual como colectivo e fazem com que a investigação produtora de relatos biográficos - frequentemente inaugurais ou longamente silenciados pelos próprios sujeitos 
e sociedades - se reconheça a si própria como terreno de emergência de identidades, identificações, novas histórias de relações sociais. Tal pensamento faz-se no horizonte não de uma relação distanciada entre investigadora e seus interlocutores, mas de uma consciência política do trabalho de investigação biográfica. É essa consciência que nos leva a imaginar os ateliês biográficos como uma "utopia concreta" capaz de dar um passo em frente relativamente a formas consensuais e assépticas de fazer pesquisa.

Sabemos que nos situamos num terreno minado, subtil, onde o perigo das interpretações explosivas espreita a todo o momento. Mas aceitamos o desafio de não renegar uma análise que, sendo polémica, tenta responder de forma mais directa à encruzilhada entre subjectividades, posições sociais e direitos cívicos no terreno.

\section{Conceito e antecedentes de práticas emancipatórias}

O conceito de emancipação significa no sentido comum "tornar-se livre de tutela", "libertar-se", "conquistar independência" e remonta ao Direito Romano onde se aplicava nomeadamente a mulheres e escravos libertos.

Nos seus desenvolvimentos teóricos contemporâneos, inicialmente forjados pelo marxismo e a teoria crítica do século Xx, este comporta um elemento de autonomização dos seres humanos que acompanha as transformações geradoras da sociedade moderna. O ser emancipado é, doravante, capaz de se reconhecer e organizar como uma força social (Marx) e tal capacidade é susceptível de ser educada (Horkheimer, Adorno). Mais recentemente, no limiar do novo milénio, são referências mundiais da teoria da emancipação dois autores de língua portuguesa: Paulo Freire e Boaventura de Sousa Santos.

Pedagogo brasileiro com larga influência no pensamento social da segunda metade do século xx, Paulo Freire propõe uma ideia de emancipação enraizada em acções humanas tradutoras do direito de existir condignamente, de se exprimir nas suas potencialidades, capacidades e diferenças. A emancipação proposta por Freire pressupõe o respeito pela pessoa, a educação popular e o multiculturalismo. O objectivo da emancipação é saber conviver na diversidade e o meio para tal reside na educação. Para Freire, a emancipação significa a conquista do poder de pronunciar o mundo, ou seja, a capacidade de produzir um saber autónomo sobre o mundo, de tornar-se actor ou actriz da sua própria história. Esse poder constrói-se no quotidiano, num processo de constante devir (em casa, na família, no trabalho, na sociedade). Também implica ter uma consciência crítica e a intenção de mudar o estado das coisas (Freire 1963, 1967, 1969). 
Para Boaventura de Sousa Santos, que coordenou um projecto internacional sobre a reinvenção da emancipação social (1999-2001), ${ }^{1}$ a emancipação no mundo actual passa por uma nova equação entre subjectividade, cidadania e emancipação. Sousa Santos defende um multiculturalismo emancipatório, baseado no reconhecimento da diferença, no direito à diferença, e na coexistência pacífica na diversidade. Segundo este autor, ao mesmo tempo que a hegemonia neo-liberal se expande à escala global, surgem formas de resistência de grupos excluídos e movimentos de aspiração a um mundo melhor, promotores de uma cidadania emancipatória. Esta assenta em iniciativas locais-globais, conectadas em rede e fomentadoras de uma nova justiça social. Como afirma Boaventura Sousa Santos no prefácio ao volume Reconhecer para libertar: os caminhos do cosmopolitismo multicultural $(2003,21)$ : uma das preocupações centrais do projecto Reinventar a emancipação social foi a renovação das ciências sociais confrontando "o conhecimento que elas produzem com outros conhecimentos (práticos, plebeus, vulgares, tácitos) que, apesar de serem parte integrante das práticas sociais que as ciências sociais analisam, são sempre ignorados por estas.”

Face à precariedade e exclusão de um número crescente de populações, e perante a banalização e normalização das formas contemporâneas de opressão, uma grande variedade de organizações civis luta em todo o mundo na perspectiva de uma transformação social, política e de desenvolvimento de cidadanias activas. Nascem assim, em vários cantos do globo, numerosas experiências de "práticas emancipatórias" inspiradas nas propostas político-educativas de autores - como Freire e Santos - capazes de associar a produção teórica à ideia de co-participação de grupos sociais desiguais. Já não se trata, pois, apenas, de produzir e acumular saber, mas de saber ler o mundo que nos rodeia e do qual somos parte activa, de maneira a agir com consciência na sua (que sempre passa pela nossa própria) transformação.

Múltiplas acções e práticas analisadas com os respectivos actores em várias culturas e continentes mostram como a emancipação pode ser uma "utopia concreta" que dá sentido às lutas contra novas formas de dominação e alienação dos mais fracos ou vulneráveis. Algumas dessas práticas têm sido fomentadas pelo "Círculo das pedagogias emancipatórias", criado em

\footnotetext{
${ }^{1}$ Este projecto deu origem à publicação de sete livros onde constam os principais resultados obtidos. Os volumes 3 e 6 são os mais directamente relacionados com a questão da emancipação de pessoas e grupos subalternos. Ver Boaventura de Sousa Santos (org.), Reconhecer para libertar: os caminhos do cosmopolitismo multicultural (2003) e As vozes do mundo (2008). Seria interessante tomar conhecimento da acção de imigrantes ou de associações de migrantes no mesmo sentido.
} 
França após a morte de Paulo Freire, em 1997. A Unesco tem apoiado tais medidas através do seu programa MOST ("Management of Social Transformation") de gestão das transformações sociais. O livro organizado este ano por Françoise Garibay e Michel Séguier sobre práticas de emancipação é um exemplo desta colaboração entre actores e decisores da transformação social. Partindo de uma reflexão sobre o encontro com Paulo Freire e o "Círculo das pedagogias emancipatórias", os vários artigos publicados neste volume apresentam experiências de trabalho concretas, conduzidas em âmbitos geográficos e culturais diferentes, guiadas pelo objectivo da capacitação, participação cívica e acção cultural.

As práticas emancipatórias são práticas pedagógicas "freirianas" que associam a produção colectiva de conhecimentos à análise de experiências específicas vividas (ou sofridas) pelos intervenientes nesse mesmo trabalho. Tais práticas são guiadas por dois objectivos principais: construir em conjunto conhecimentos úteis à acção e reflexão sobre a emancipação a partir de experiências internacionais diversas; e interligar e reforçar redes de práticas pedagógicas, concebendo e concretizando modalidades de diálogo aprofundado entre diferentes categorias de actores - nomeadamente entre universitários e a sociedade civil. Este segundo objectivo comporta ainda a promoção de novas formas de criação, expressão e difusão dos conhecimentos e competências construídas (Garibay e Séguier, 2009: 58).

Os impulsionadores das práticas pedagógicas emancipatórias são investigadores de várias áreas das ciências sociais e humanas em diferentes países. O seu trabalho faz-se em estreita ligação com os actores no terreno. Por exemplo, habitantes de uma zona rural do Nordeste brasileiro organizados num movimento social de participação na gestão pública local; membros de uma empresa de "inserção pela economia" no Quebeque; grupos indígenas mexicanos; bairro de habitação social em França ou favela do Rio de Janeiro. Todas estas experiências são realizadas em grupo, pelo cruzamento dos saberes e práticas diferentes de cada um (diferentes "categorias" de actor), na desconstrução e reconstrução de posições, estatutos e pontos de vista de partida (modelo da participação/co-construção). O horizonte teórico e prático destas práticas está na construção solidária de um saber útil, concreto, baseado no encadeamento entre necessidade-vontade-saber-poder.

É neste quadro teórico que situamos o dispositivo de biografização emancipatória dos migrantes aqui apresentado. Ele não nasceu, no nosso trabalho, de um objectivo pedagógico ou político de partida. Antes surgiu como resultado da experiência de investigação antropológica que tenho vindo a desenvolver junto de migrantes de origens diversas em terrenos 
diferentes. ${ }^{2}$ Estes trabalhos caracterizam-se por uma abordagem biográfica das experiências de migração, atenta aos processos de reconfiguração identitária e sofrimento/resiliência dos migrantes. Porque é necessária uma escuta atenta e curiosa para que as histórias de migração se produzam, a pesquisa universitária constitui um terreno de emergência de relatos nunca antes produzidos. Tal facto obriga a tomar em conta, na análise do nosso objecto de estudo, os sujeitos de diálogo nele implicados. Foi através de um genuíno e solidário interesse pelas histórias dos migrantes que constatámos como a escuta representa o grau zero da emancipação pelo trabalho biográfico. Da mesma forma verificámos como ela é condição necessária para as etapas do processo emancipatório que se lhe seguem, e como os actores aí envolvidos são co-construtores do saber advindo.

\section{A biografização como instrumento de reconfiguração identitária e de resiliência dos migrantes}

Em ciências sociais a migração é raramente analisada a partir do ponto de vista dos migrantes. Mais precisamente, os estudos sobre emigração e imigração esquecem com frequência a experiência de mobilidade e de transição que corresponde a uma ruptura biográfica e a um trabalho de reconstrução das identidades. Quando um estudo etnográfico clássico se dá por terminado neste terreno, o impacto da investigação sobre a vida dos migrantes entrevistados também se perde (um estudo sobre difere de um estudo com os migrantes). Em contrapartida, neste artigo é proposta uma abordagem que toma em consideração a perspectiva experiencial dos migrantes, bem como o encontro dialógico entre a investigadora e seus interlocutores. Esta postura introduz uma perspectiva relacional, baseada numa metodologia de diálogo capaz de analisar em conjunto com os migrantes os respectivos relatos biográficos e seu efeito emancipatório.

Dois trabalhos desenvolvidos com migrantes de diferentes origens e em dois terrenos diversos, bem como uma experiência de ateliê biográfico realizado com alunos do Mestrado em Educação e Contemporaneidade na Universidade Estadual da Bahia, ${ }^{3}$ permitiram verificar a produção de três efeitos principais da abordagem biográfica, com pertinência social: 1) a validação dos testemunhos dos migrantes frequentemente anulados por estereótipos e estigmatizações 2) a valorização da experiência vivida e contada,

\footnotetext{
${ }^{2}$ Trabalho de Doutoramento junto de emigrantes portugueses em França, EHESS, 2003 (FCT, BD/3365/94); pós-doutoramento sobre a "Consulta do Migrante" no Hospital Miguel Bombarda em Lisboa, ICS e CEAS/ISCTE (FCT, BPD/15011/2002 e BPD/26099/2005).

${ }^{3}$ Ateliê realizado nos dias 26 e 27 de Abril de 2006 com os alunos de Mestrado em Educação e Contemporaneidade, da linha de pesquisa biográfica.
} 
via de acesso para a consciencialização das potencialidades dos actores sociais; 3) a co-construção de saber e de novas formas de relação à alteridade. A validação dos testemunhos corresponde à sua aceitação e reconhecimento "tal qual", oposta a estigmatizações comummente reproduzidas mesmo por quem se propõe trabalhar junto de populações migrantes. Validar significa aceitar como são, sabendo que serão diferentes uma vez criadas as condições para tal. A valorização permite aos migrantes interlocutores tomar consciência do seu poder improvável segundo a sociedade de exclusão. Valorizar traduz-se em fazer mais e reconhecer-se capaz. Passar à acção. A co-construção faz-se entre entrevistador e entrevistado, entre cientistas sociais e sujeitos no terreno.

A metodologia aplicada consistiu em entrevistas biográficas e na análise de narrativas autobiográficas (orais e escritas). A primeira realizou-se com emigrantes portugueses em França, a segunda com imigrantes em Portugal (oriundos de diferentes países europeus, africanos e da América Latina), pacientes da "Consulta do Migrante", acima referida. Por sua vez, o ateliê biográfico levado a cabo no Brasil baseou-se em dois exercícios de escrita autobiográfica partilhada oralmente pelo grupo de alunos: ${ }^{4}$ um primeiro texto iniciado com a expressão "Eu nasci...", e um segundo texto sobre uma experiência traumática a escolher por cada um dos participantes.

Tanto no terreno parisiense como na "Consulta do Migrante" em Lisboa, as entrevistas biográficas foram realizadas por minha iniciativa. Após apresentar brevemente o objectivo do estudo e tendo obtido, no caso da consulta, autorização oficial da Direcção do Hospital Miguel Bombarda (no seguimento da avaliação do meu pedido pelo Conselho de Ética), pude entrevistar homens e mulheres, de idades diversas, que aceitaram contar a sua história. Os encontros com os utentes da consulta fizeram-se fora do hospital, com conhecimento da direcção da consulta mas de forma totalmente independente do trabalho da equipa clínica. Há que referir, aliás, que as minhas relações com os membros deste serviço foram sendo pautadas por uma tensão crescente que não desembocou em qualquer diálogo efectivo apesar das iniciativas tomadas nesse sentido no âmbito do projecto que me havia levado ao terreno da "Consulta": a organização de um ciclo de conferências sobre migração, saúde e diversidade cultural (que deu origem a um livro editado pelo ICS), e um curso de actualização sobre práticas terapêuticas e diversidade cultural (igualmente no ICS). Aos meus olhos, o dispositivo terapêutico proposto pela consulta reproduzia acriticamente

\footnotetext{
${ }^{4}$ Pedi autorização aos participantes para citar os textos produzidos no ateliê. Esta foi-me concedida por todos, sem excepção. Os originais foram-me cedidos por quinze alunos.
} 
um modus operandi da psiquiatria médica, longínquo das preocupações básicas da psiquiatria cultural e dos próprios pacientes...

No caso do ateliê biográfico com os alunos da UNEB, este fez-se no quadro de um convite do coordenador do programa de pós-graduação, Professor Elizeu Souza, e com o objectivo de pôr em prática um exercício de biografização em grupo. ${ }^{5}$

Em todos estes casos acolhi os testemunhos que me foram confiados, juntamente com as emoções, estados de espírito, transformações revelados durante a interacção. $\mathrm{O}$ alcance deste acolhimento pode confundir-se com uma situação terapêutica mas esse não foi o propósito de partida, nem do encontro, nem da produção dos relatos em si.

Cada interlocutor estabeleceu os termos do diálogo de acordo com a sua disponibilidade, receptividade, investimento na auto-reflexividade aí envolvida. Também houve casos em que as entrevistas me foram negadas, nomeadamente por dois pacientes da consulta: um jovem paciente africano cujo irmão (com quem vivia, de quem dependia e com quem eu falei) proibiu a entrevista dizendo que o seu caso era muito grave, "neurológico", acarretando uma grande responsabilidade para mim; uma paciente africana refugiada da Guiné, que apesar da empatia e simpatia manifestadas, preferiu não falar da sua vida "muito triste".

No ateliê biográfico participou um aluno que se manteve calado - apesar de mostrar uma grande atenção e silencioso interesse - até ao último dia, momento em que finalmente aceitou o meu convite para falar. Aí testemunhou da importância desse encontro na sua vida: "Estar aqui é estar do lado dos vencedores”. Embora não tivesse escrito os textos autobiográficos, viveu com intensidade tudo o que se passou. Disse então, comovido, que mesmo só ouvindo os colegas e observando a dinâmica de grupo, encontrou respostas para um problema difícil que estava a enfrentar com a sua filha surda-muda de dois anos. Não sabia como lidar com a diferença da sua bebé e confrontava-se com um sentimento de vergonha e rejeição em relação a ela. Uma das colegas presentes tomou a palavra para dizer que era professora de crianças portadoras dessa deficiência e ofereceu os seus préstimos para ajudar. Este foi um momento muito intenso do ateliê em que todos vivemos o efeito exponencial da partilha mesmo junto dos que não participaram activamente, de viva voz.

Em todos estes contextos a minha postura foi a de uma interlocutora atenta, respeitadora, permeável tanto às ideias como às sensações, e tanto às

\footnotetext{
${ }_{5}$ Fui formada para este tipo de exercício pelas Professoras Jeanne-Marie Rugira, Marie-Christine Josso e Christine Delory Momberger, em diversos seminários pontuais em Portugal e França.
} 
palavras como aos silêncios. Esta postura permitiu acolher não só o universo referencial dos migrantes (valores, crenças, representações) mas também os estados em que eram apresentados (alegria, tristeza, ressentimento, confusão). A troca de informações não foi aqui meramente informativa, e a sua análise não se limitou ao tema da performatividade dos testemunhos entendida como estratégia num jogo de poderes entre entrevistadora e entrevistados. Ou seja, não se resumiu a entender os relatos como intencionalidades calculadas. Ousámos entrar no domínio de uma relação que só aconteceu porque o outro lado aceitou a proposta. São os meandros dessa relação dialógica que alimentam, aliás, a postura acima indicada.

Embora todas as narrativas produzidas no ateliê tenham focado a questão da migração, faço neste artigo apenas referência a um dos textos, por mencionar explicitamente a experiência de mobilidade do seu autor como tendo sido formadora de uma nova percepção de si. O trecho que se segue mostra como o relato biográfico do enunciante corresponde a uma auto-consciência dos efeitos da trajectória vivida sobre a sua identidade pessoal, profissional, política, e de género.

Eu nasci na zona rural do Estado do Paraná, sul do Brasil. Sexto filho dos sete que tiveram meu pai, um imigrante baiano domador de burros bravos e uma descendente de italianos que arrancava mandioca a partir das 4 horas da manhã. Aos três anos tive minha primeira queimadura grave de uma série. [...] Aos quatro andei de trem pela primeira vez, quando fui morar em São Paulo. (...) Nesta época já ia com meus irmãos recolher alimentos no final da feira. Fazíamos parte das estatísticas dos que estão abaixo da linha da pobreza. Reprovei a $7^{\mathrm{a}}$ série em História e acabei por me formar em História. Trabalhei como engraxate, sorveteiro, sapateiro (onde inalei cola involuntariamente), metalúrgico, fiz xampu, fogões, Xerox, redator de jornal e alfabetizei adultos, onde me encontrei como professor formador de professores e de adolescentes. Andei de carona, de trem, de ônibus, e muito a pé... Dormi em praças, estações rodoviárias e ferroviárias, além de muitos hotéis de quinta categoria. Militei em movimento estudantil secundarista, universitário e em sindicatos classistas de metalúrgicos e professores. Uma vez recebi uma proposta para trabalhar na campanha de Maluf para ganhar muito dinheiro e recusei por ideologia (jamais me arrependi).

[...] Certa vez migrante recém-chegado em Três Lagoas do Mato Grosso do Sul, sem conhecer ninguém, entrei numa passeata só de mulheres do dia 8 de Março e fiz amizades, arrumei emprego e moradia em menos de quinze minutos. Acredito na beleza da vida e na grandeza das pessoas.

(Gerson do Carmo Argolo, Salvador, 27/4/2006) 
A leitura em grupo de cada um dos textos consistiu num segundo momento de consciencialização. Desta feita, foi o eco das observações e sugestões dos colegas que potenciou uma compreensão mais vasta dos percursos e vivências de cada um. A pertinência e interesse da partilha dos relatos autobiográficos residem neste efeito exponencial de compreensão e atribuição de sentido. Disso mesmo falaremos mais adiante, na apresentação do dispositivo emancipatório que nos ocupa.

Também quanto às narrativas escritas a que tive acesso junto dos migrantes entrevistados em França, apenas citarei aqui um só caso. Trata-se de um interlocutor que deu início à escrita da sua história de vida na sequência das nossas entrevistas. ${ }^{6}$ Este emigrante português em Paris já havia escrito romances, poemas e dossiers autobiográficos recheados de documentos e fotografias que sempre levava para as nossas entrevistas. Estas realizaram-se ao longo de vários anos, deram lugar a dezenas de cassetes gravadas e milhares de folhas de papel autobiográficas. Ainda hoje estamos em contacto, e ainda no presente (embora mais ocasionalmente) recebo dossiers biográficos deste transmontano nascido em 1935. As conversas com António $\mathrm{Cravo}^{7}$ revelaram ser o que chamo de "diálogos de vida" (Lechner, 2007), no sentido de diálogos que, ao versarem sobre a sua trajectória biográfica, criaram a oportunidade de resgatar o sentido de uma vida marcada pela ruptura. Tais diálogos não ignoram os silêncios voluntários e involuntários na interacção. Apesar de serem conversas inaugurais de uma atribuição de sentido procurada pelos meus interlocutores, sempre comportam também histórias que se não podem contar, que são difíceis de ouvir, ou que - uma vez transgressoras de uma qualquer interdição política ou moral -, desafiam os estatutos de quem diz e de quem ouve. Isto mesmo aconteceu com Cravo, a propósito de um dos seus dossiers biográficos que levou para a entrevista mas que não abriu, dizendo "Este não lhe posso mostrar". Tratava-se do dossier intitulado "O processo", referente à sua fuga de Portugal em 1974, ao seu trabalho como administrativo da Presidência da República durante o regime pré-democrático, e à sua indemnização pelo Estado Português nos anos 1980. Recentemente tive a oportunidade de falar deste assunto com o meu interlocutor. Por iniciativa própria, Cravo disse-me que "esse tema é um hiato nas nossas conversas". Ao que eu respondi com uma provocação perguntado porquê. "Choca-me muito", repostou. "Não me arrependo de nada do que fiz mas acho tudo muito chocante." Visivelmente perturbado

\footnotetext{
${ }^{6}$ Caso desenvolvido na minha tese de doutoramento "Enfants de l'eau: la reconstruction de l'identité en situation d'émigration. Le cas des Transmontanos en région parisienne" (EHESS, Paris 2003).

7 Pseudónimo de Jaime António Gonçalves, que estou autorizada a citar.
} 
com a sua "revelação" (que já não o era para mim desde o início), este depoimento dá que pensar nos limites ultrapassáveis dos diálogos apesar das interdições (não apenas nas barreiras inultrapassáveis entre pessoas). Em 1997 Cravo levou o dossier para a nossa entrevista sem o abrir. Em 2009, abriu o dossier sem o levar. Num momento como no outro pude adivinhar o que lhe era impossível contar. Mas fiquei-me por aí. Por que razão teria eu de defender uma qualquer posição face ao depoimento do meu interlocutor? São os cientistas sociais e académicos supostos vestir a pele de juízes da história? Mais importante é reconhecer (sem receio) que se pode ser capaz de tocar o intocável sem vitimizar uns ou diabolizar outros. É este igualmente um dos desafios da pesquisa biográfica sempre profundamente contextualizada nos tempos da memória e da história.

O caso de António Cravo reveste-se da particularidade de acumular a experiência de migração ao facto de ser um "Zorro", ou filho ilegítimo (como se diz em Trás-os-Montes), e de ser um presumível descendente de judeus convertidos, nascido em plena vigência do excludente slogan Salazarista "Deus, Pátria, Família". Por estas três razões, Cravo diz sentir-se um bastardo ao cubo: registado como "indigente" ao nascimento; inadequado ao modelo nacional do regime político da época; e, mais tarde, migrante forçado a deixar o país.

Foi no exercício de revisitação da sua trajectória biográfica, bem como na escrita das suas experiências de migrante, que este homem construiu um equilíbrio (após uma fase de desorientação existencial) consciente do peso do contexto social e político no seu percurso de vida, primeiro, e depois, na possibilidade de conquistar uma nova percepção de si.

Num texto intitulado "No equilíbrio do vai e vem", ${ }^{8}$ ele diz:

[...] Com o progresso político do seu país [Cravo fala na terceira pessoa], ele pode adquirir um novo estatuto de cidadania no seu país de acolhimento. [...] Deixou assim para trás o seu estatuto de emigrante, pelo menos no princípio e no direito que atravessam as fronteiras dos quinze. Agora sente-se um homem universal. Nesta universalidade e na sua especificidade comunitária, encontra-se confortável entre dois homens, num só homem. No equilíbrio deste pêndulo, e pela força do tempo, descobriu, finalmente, um novo equilíbrio nesta nova forma de viver num vai e vem sem renegar as suas raízes e tendo um sentimento de gratidão para com o país que o acolheu.

Cravo fez a experiência de biografização após a ruptura vivida na emigração, mesmo antes da minha proposta nas entrevistas, motivado pelo

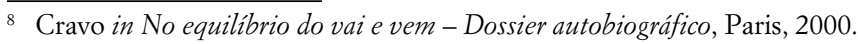


sentimento de perda das raízes e pela experiência de exclusão em França. Os seus sentimentos de perda, de ter sido traído pela vida, de exílio interior, de marginalização, acompanharam o desenvolvimento de uma nova imagem do mundo e de si como pessoa, como português, como cidadão. Na situação de migração, tal experiência corresponde muitas vezes a um estranhamento de si, comummente sentido pelos migrantes tanto em relação ao país de origem, como ao de imigração. $\mathrm{Na}$ experiência deste vazio, Cravo revisitou a sua história pessoal dando início a um processo de produção de sentido para o sofrimento que sentiu. A experiência da perda de referenciais simbólicos, linguísticos e culturais, foi por ele vivida como uma oportunidade de recuperação substancial da sua história pessoal mas também de reinvenção de uma identidade de português e de transmontano em França. E nesse movimento propriamente contra-melancólico, Cravo iniciou uma procura de afirmação da sua identidade de cidadão no mundo. Ele diz mesmo ser um imigrante português diferente dos outros mas que assume a sua identidade de imigrante português em França:

Podemos ser portugueses em França e não trabalhar nas obras. Sinto-me um imigrante e escrevo em nome do imigrante. E afirmo a minha identidade de imigrante porque vejo a nossa comunidade seguir dois caminhos paralelos divergentes. De um lado o imigrante que avança lentamente, que sobe a montanha pouco a pouco -, e o nosso país não é capaz de reconhecer a distância percorrida entre o pé e o topo da montanha. Do outro, um grupo de portugueses em França que olham de longe o caminho da comunidade portuguesa, que se servem dela para ganhar o pão mas que têm vergonha de se misturar a eles... vergonha! São dois caminhos que não se cruzam. ${ }^{9}$

Com o seu trabalho autobiográfico, Cravo procura atingir um triplo objectivo: "Preservar a memória, tomar consciência das nossas capacidades individuais e colectivas, e acabar com uma certa ideia do emigrante". Ao escrever a sua história de vida, quer garantir a transmissão da cultura que herdou e, ao mesmo tempo, contribuir para novas maneiras de ser português e transmontano. Como pano de fundo dessa construção escolhe os três níveis - local, nacional e internacional - da sua pertença identitária. Para tal, sugere a promoção da cultura e da língua portuguesa no seio das comunidades migrantes e o intercâmbio com Portugal. Cravo sublinha igualmente a importância de "conjugar esforços entre os residentes em Portugal e os emigrantes do presente e do futuro, os luso-descendentes". Procura ainda construir esta forma de ser português, a partir da realidade

${ }_{9}$ Cravo in No equilíbrio do vai e vem, Paris, 2000. 
quotidiana da sua vida de homem de trabalho, "[...] jamais indiferente às dificuldades, à luta corajosa e ao sofrimento (tantas vezes esquecido) dos nossos concidadãos." 10

Guerras, pobreza, violência, as partidas, fugas ou exílios, as viagens e desembarques mais ou menos traumáticos, os naufrágios, bem como os laços cortados com a família, com a língua materna, são cenários de vivência experimentados por muitos migrantes. Tais experiências podem chegar a dissolver a vontade de viver, para alguns, ou podem estilhaçar as existências, criando verdadeiros estaleiros biográficos e identitários que exigem um herculeano trabalho de reconstrução. O caso de Cravo é um exemplo desse esforço. A produção de um novo discurso sobre si e sobre o mundo, ou a passagem do silêncio à palavra articulada, acompanha o processo de resiliência que reconstrói os sujeitos. Este pode traduzir-se na simples resistência às condições opressivas, na ultrapassagem das dificuldades ou numa verdadeira emancipação. Para que esta última aconteça, é imprescindível uma relação de confiança com um interlocutor respeitador que permita a realização dos diálogos de vida. Ou seja, uma relação instauradora da possibilidade de resgatar o sentido das rupturas biográficas e experiências vividas.

\section{Modelo analítico do processo de biografização aplicável na área das migrações}

Tanto no terreno parisiense como na "Consulta do Migrante" em Lisboa, o protocolo de entrevista utilizado foi o mesmo: uma conversa informal e livre, nos locais escolhidos pelos meus interlocutores, sobre os seus percursos biográficos a partir da questão da migração. Acompanhando o fluxo das conversas e respectivos desvios imprevistos, estas entrevistas guardaram um eixo comum composto de subtemas relevantes para compreender as trajectórias de migração: família e local de origem, infância, escolaridade (ou não), projectos, trabalho, uniões (ou não), decisão de migrar, experiência de emigração, imigração, contacto com uma nova língua, cultura, contexto social, habitação, trabalho, saúde, percepção dos outros, de si próprio como migrante, condições de vida presente, planos para o futuro.

No trabalho específico com os pacientes da "Consulta do Migrante", este eixo procurou igualmente visitar os motivos do pedido de ajuda psicológica, os rostos do mal-estar sentido, a escolha deste serviço específico (na maior parte dos casos não se tratou de uma escolha mas de um encaminhamento proporcionado por serviços de informação aos migrantes ou

${ }^{10}$ Cit. de António Cravo, em entrevista à autora, realizada em 1998. 
serviços religiosos). As entrevistas realizaram-se fora do hospital mas também tive a oportunidade de participar em algumas consultas com pacientes cuja biografia e experiência migratória muito contribuem para compreender as suas aflições.

A relação que permite instaurar o dispositivo emancipatório dos migrantes pelo estudo biográfico, traduz-se num encontro bem sucedido entre os universos simbólicos diferentes dos migrantes e pesquisadores. Ela constrói-se segundo uma lógica não da tolerância (que não faz senão sublinhar uma desigualdade de partida entre as pessoas) mas sobre a base de uma abertura, de uma curiosidade, do respeito. Constrói-se ainda sobre o pressuposto que todos são co-construtores da sociedade e da coesão. Quando acontece, a relação instauradora transforma os sujeitos ao mesmo tempo que os torna mais conscientes do seu potencial, poder, e papel na vida colectiva.

Este é um aspecto que apresenta nuances a analisar no que diz respeito às diferentes posições de saber e poder dos actores envolvidos. Apesar dos estatutos diferentes dos diversos intervenientes, temos a experiência de ver as fronteiras fundirem-se por momentos em brechas de liberdade face aos lugares sociais ocupados "lá fora" por cada um. De facto, nestes encontros, surgem epifenómenos conversacionais que quebram certezas e representações petrificantes das identidades. À partida, os sujeitos, mesmo os motivados para a compreensão de si e dos seus itinerários biográficos, encontram-se com frequência presos a histórias e papéis que os designam. Como se fossem objectos, as pessoas são ditas e ditadas por discursos pré-fabricados. Segundo André Vidricaire (2009: 91), especialista das práticas emancipatórias pela narrativa biográfica: “ . .. antes mesmo de tomarem a palavra para falarem de si, para se descobrirem e se revelarem, todos (...) estão já ditos por histórias que se lhes colam à pele." O sujeito adquire formas (nas narrativas) que traduzem representações da individualidade humana próprias a cada época histórica e domínio cultural, bem como a diferentes concepções do espaço público e privado, da relação entre os indivíduos o social e o político, da relação do Homem a si próprio (Delory-Momberger, 2004: 73).

Pelo contrário, nos exercícios de biografização (seja nas entrevistas face a face ou nos ateliês), surgem as condições de possibilidade de confrontar tais discursos pré-fabricados, herdados, adoptados acriticamente pelos sujeitos. Com esta abertura surge uma outra: o vislumbrar de novas identificações, logo, de novas percepções de si e dos outros. Na situação "extra-quotidiana” do relato biográfico voluntário dos migrantes, produz-se igualmente uma abertura face a formas institucionalizadas de investigação sobre migração. Não penso que a iniciativa de o fazer sirva apenas estraté- 
gias políticas e interesses calculados dos migrantes. Nos contextos de trabalho em que encontrei pessoas disponíveis para falar de seus percursos biográficos, o que as motivou a aceitar o pedido e, depois, a falar de si, foi manifestamente uma grande solidão e desencontro com instâncias públicas como o serviço da "Consulta do Migrante". Esperanza, ${ }^{11}$ uma das pacientes que entrevistei, disse-me mesmo: "Agora que estou a falar contigo sobre isto, sobre o meu país, a minha família, a minha vida lá, entendo melhor tudo o que me aconteceu." (entrevista)

Eis como se processa o trabalho em grupo com os migrantes: este pode reunir pessoas de diferentes origens, diferentes idades, homens e mulheres simultaneamente. ${ }^{12} \mathrm{O}$ trabalho ganha tempo em ser feito numa só língua, supostamente a do país de imigração, mas pode realizar-se também com a ajuda de tradutores, se as condiçõos necessárias para tal se reunirem.

De forma análoga aos "ateliês biográficos de projecto" (Delory-Momberger, 2006), os ateliês biográficos com migrantes fazem-se no quadro de um trabalho intensivo de um, dois ou três dias, onde os relatos individuais são objecto de uma exploração e socialização. Estes implicam exercícios de escrita de si e de compreensão do outro. Limitamo-nos aqui ao trabalho escrito e oral mas podemos considerar também ateliês de outro tipo nomeadamente os que fazem recurso à percepção corporal.

Após a apresentação do "programa" e do "contrato" do ateliê, os participantes são convidados a escrever um pequeno texto autobiográfico que pode incidir sobre diferentes temas e etapas das suas trajectórias de migração. Num momento seguinte, e depois de estabelecer uma regra de escuta atenta, respeitadora e sem julgamentos, cada um lê o seu texto em voz alta, na ordem de disponibilidade que o seu à vontade lhe oferece. Aqueles que escutam devem anotar as impressões, ideias, sensações, comentários que a leitura do colega lhes sugere, para depois os expôr ao grupo. Pode ainda ser feito um exercício suplementar de segunda leitura. Este serve para fazer a experiência de "processo" na compreensão dos relatos e na partilha: a forma como se lê e ouve aquilo que foi escrito não é a mesma no primeiro e no segundo momentos.

À imagem da "arbre à palabre" africana, cada participante oferece a sua percepção sobre os relatos lidos, o que produz um efeito exponencial de consciencialização (pelo questionar e relativizar da experiência de cada um), formação (aprendem uns com os outros) e transformação de si (descoberta de novas possibilidades, horizontes, da capacidade criativa de se "inventar"

\footnotetext{
${ }^{11}$ Nome fictício.

${ }^{12}$ A questão do género não é aqui tomada em conta.
} 
a si próprio). O clima de respeito no qual os comentários são feitos, bem como a confrontação com experiências diferentes, permeabiliza os sujeitos. Todos verificam como as experiências (mesmo as mais míticas ou fundadoras de identidades julgadas fixas) são "filtradas" por representações nascidas nos contextos de vivência.

Esta é a implicação teórica de maior relevo das abordagens biográficas. O exercício de biografização faz saltar estereótipos incorporados libertando os sujeitos para novas possibilidades de acção e afirmação social. Disso mesmo dá conta a corrente das histórias de vida em formação, cujo pioneiro foi Gaston Pineau nos anos 1980. Os pressupostos teóricos que inspiram as démarches de formação pelas histórias de vida assentam, por um lado, na experiência que o sujeito faz de si através da produção do seu relato e, por outro lado, na dimensão de projecto constitutiva da história de vida. Neste sentido Pineau considera que as histórias de vida são "artes formadoras da existência" ou seja, elas formam transformando ao mesmo tempo que transformam formando os sujeitos que se contam (Pineau 1996 [2006]).

A nossa experiência de trabalho com os migrantes mostra como as várias técnicas do método biográfico são também uma arte de invenção de novas formas de alteridade no diálogo com outrem. Ao ser feito num clima de confiança, este parece inventar a parte de originalidade do encontro e permite acolher a imprevisibilidade resultante do face a face entre pessoas de mundos sociais e culturais diferentes. Tal acontecimento só pode ocorrer quando a escuta e a enunciação se libertam de posições hegemónicas rígidas ou dogmáticas. Quer dizer, quando o encontro também é entendido como potencialmente formador e transformador. Caso contrário não há sequer encontro.

Este facto não é de somenos importância para ninguém, e muito menos para pessoas pertencentes a grupos vulneráveis ou marginalizados, como é o caso de muitos migrantes. E se a época em que vivemos permite, em determinados contextos sociais, fazer a experiência de um "eu" mais autonomizado - ou, em qualquer caso, mais consciente da capacidade de "trabalhar" a sua identidade/sua existência -, talvez estejamos a tornar-nos espectadores da nossa própria capacitação (individual e colectiva) para transformar as nossas vidas num sentido construtor de novas coexistências na diversidade.

Os cenários históricos, sociais e culturais estarão sempre aí para os humanos como um oceano está para os peixes do mar. Mas à escala dos indivíduos, a existência humana torna-se passível de diversas "aclimatações". E justamente porque no universo humano, natureza e cultura estão intimamente relacionadas, as vidas dos indivíduos não são nunca apenas puras versões 
pré-determinadas pelos contextos "exteriores": contextos "interiores" também condicionam as formas de vida humana. No entanto, tal evidência é mais fácil de aceitar quando as sociedades são capazes de pensar o peso dos contextos exteriores sobre as interioridades. Ou, dito de outro modo, quando as subjectividades são capazes de falar e se fazer ouvir.

$\mathrm{O}$ interesse e a escuta que podemos manifestar face aos interlocutores migrantes despertam ângulos mortos na compreensão dos seus percursos relatados. Os relatos, por sua vez, fazem descolar as velhas histórias que se lhes colam à pele. Claro está, estas não traduzem apenas identidades cristalizadas que petrificam os sujeitos, mas são também a marca e o reservatório de várias opressões. A velha pele descolada é o rasto de relações históricas de dominação entre grupos e países desiguais. Sem eufemismos, na história da Europa, a opressão sempre se fez pelos brancos sobre os outros! (Beneduce, 2009). E ainda no presente do "velho continente", o encontro com os migrantes originários de ex-colónias reactualiza estas relações de dominação. Assim, trazer luz sobre os recantos escondidos de cada uma destas vidas, significa tocar antigas feridas históricas carregadas pelos indivíduos e as sociedades.

Neste sentido, os diálogos de vida libertam tanto a nível pessoal como social. Os migrantes podem tornar-se autores e actores de novas formas de se dizerem, de viverem, e de participarem na vida colectiva, mas também podem tornar-se autores e actores de novas formas de coexistência entre grupos pertencentes a lados opostos das barricadas do passado. Esta é uma versão colectiva da resiliência passível de aproximar pessoas e grupos diferentes por vezes partilhando histórias de conflito.

A partilha de experiências cria novos universos de pertença, de identificação, cria formas de participação reconhecidas entre pares e pela sociedade em geral. E a nova percepção de si e dos trajectos vividos transforma-se em resiliência e capacitação. Da posição de "vítimas" (ou aliens, segundo a denominação oficial dos EUA), os migrantes podem passar a ganhar o reconhecimento necessário para se tornarem cidadãos plenos no país de imigração. É através deste triplo efeito de consciencialização-capacitação-participação que a relação de diálogo emancipa. E aí se produz a coesão social. Neste sentido, as histórias individuais formadas e transformadas pelos diálogos de vida são também histórias de novas relações e laços sociais.

Este trabalho de grupo produz ainda resultados individuais e colectivos a partilhar também com o público em geral. Nomeadamente através da publicação dos textos autobiográficos redigidos, acompanhados de uma apresentação do procedimento metodológico adoptado e de uma análise 
teórica adequada aos objectivos específicos de cada ateliê. Os resultados partilhados permitem dar a conhecer as experiências concretas dos migrantes (e não presumidas, julgadas ou idealizadas), e das relações entre estes e o país de acolhimento, bem como entre os países de emigração e imigração dos seus autores.

\section{Perspectivas éticas e sociopolíticas das práticas de biografização junto de migrantes}

Em consequência das abismais assimetrias socio-económicas entre ricos e pobres, e também graças às facilidades de comunicação actuais, as migrações internacionais mobilizam hoje mais de 200 milhões de pessoas fora do país que as viu nascer. Vista a dimensão planetária do fenómeno das migrações e dados os seus problemas políticos, culturais e éticos, impõe-se a premente necessidade de procurar soluções onde elas se encontram.

É nesta perspectiva que se tornam pertinentes os estudos e trabalhos de investigação que visam contribuir directamente para a participação dos migrantes mediante um melhor conhecimento das suas necessidades e das suas potencialidades, tanto em proveito próprio, como para a colectividade.

Para tal, há que reconhecer o peso político das biografias de migrantes. É evidente que as histórias de migração têm um papel a desempenhar na compreensão da vida política e moral das nossas sociedades. Tal como afirma Kenneth Plummer no contexto dos testemunhos privados que estudou: "As histórias que contamos sobre as nossas vidas estão profundamente implicadas na mudança moral e política, e as narrativas cambiantes do eu ou da identidade carregam um potencial de transformação radical da ordem social. As histórias contribuem para mudar vidas, comunidades, culturas. Estas mudanças são sinais de um novo modelo político emergente [...] Tal política surge sob formas diferentes, com várias - frequentemente contraditórias - denominações: política da diferença, pluralismo radical, comunitarismo, novo liberalismo, política cultural, vida política. Resumindo, está a ocorrer uma radical, plural, democrática, contingente, participativa, política de escolha de vida e das diferenças." (Plummer, 2003: 38 , minha tradução). ${ }^{13}$

\footnotetext{
13 The stories we tell of our lives are deeply implicated in moral and political change and the shifting tales of self and identity carry potential for a radical transformation of the social order. Stories work their way into changing lives, communities and cultures. Such changes are signs of a new pattern of politics emerging. [...] This new politics comes in a plethora of forms and labels, moving under various, often contradictory, names: a politics of difference, radical pluralism, communitarism, a new liberalism, cultural politics, life politics. In short, a radical, pluralistic, democratic, contingent, participatory politics of human life choices and difference is in the making.
} 
As práticas emancipatórias junto de migrantes permitem conhecer com os próprios - e não à distância, de forma asséptica - o potencial de mudança citado. Os relatos de migração reflectem, interpretam e constituem as suas realidades sociais. Através deste dispositivo, os sujeitos produzem "mapas narrativos do mundo social" (Melvin Pollner, 1996) que produzem novas subjectividades e relações sociais, logo, que merecem ser tomadas em conta pelos analistas sociais e instâncias políticas.

Existe também uma dimensão histórica importante no trabalho biográfico com migrantes. Trata-se de um lugar de re-visitação dos traumatismos. Entendidos como experiencia vivida e como tentativa de compreensão de algo que se torna presente de forma enigmática (em sonhos nocturnos, aflições, repetições neuróticas, pânico ou medos), os traumas revisitados indicam a possibilidade de fazer uma história que não é apenas referencial (baseada sobre modelos conhecidos) mas que se resitua na compreensão do incompreensível (Caruth, 1996: 11). Isto significa que a possibilidade de uma história registada exige um trabalho de luto individual e colectivo. $\mathrm{E}$ a análise social pode contribuir para isso tanto quanto o podem os encontros terapêuticos inter-culturais. Veja-se, a este propósito, o trabalho teórico e prático de terapeutas culturais e antropólogos da saúde, como Marie-Rose Moro, Roberto Beneduce, Sushrut Jadhav (in Lechner, 2009).

O quadro de uma entrevista biográfica ou de um ateliê de escrita autobiográfica é, pois, um lugar de testemunho das existências num sentido histórico. Os migrantes tomam consciência dos conflitos mais vastos que atravessam as suas vidas: as desigualdades sociais entre os diferentes grupos sociais no país de origem; a influência do clima político na decisão de partir; questões de género e de cultura tal como o estatuto das mulheres, ou a não-aceitação de um destino tradicional submetido às convenções sobre o casamento e a família, por exemplo. Desta forma, o testemunho registado é, simultaneamente, uma possibilidade de enunciação, de consciencialização e de tomada de decisão ou acção cívica.

No terreno, e independentemente dos contextos específicos de investigação - se é uma associação, um serviço terapêutico, um bairro ou um ateliê biográfico - o dispositivo biográfico transforma-se rapidamente numa epistemologia. Ele convida-nos a sermos permeáveis a um saber que emerge dos relatos e do encontro entre o investigador(a) e os seus interlocutores e que é capaz de contradizer certezas e ideias feitas sobre procedimentos teóricos e metodológicos institucionalizados.

A relevância deste saber é tanto maior quando se sabe que este encontro mais "autêntico" entre pesquisadores e "pesquisados" constrói pontes de contacto onde normalmente encontramos conflito e discriminação. Sabemos 
como, uma vez chegados ao país de acolhimento, após a odisseia das partidas e das viagens, os migrantes fazem percursos marcados por experiências de incompreensão, de desigualdade, injustiça, pobreza, exploração no trabalho, exclusão, racismo. Tais experiências são guardadas, na maioria das vezes, em silêncio, na solidão. Por isso, os migrantes que encontram a possibilidade de contar as suas histórias perante um ouvinte atento e interessado encontram uma oportunidade de libertação. E o facto de ser um/a universitário/a a interessar-se pelas suas vidas, aumenta ainda essa sensação. Como a já citada paciente da "Consulta do Migrante" escreveu num correio electrónico que me enviou (em resposta ao meu pedido de autorização para citar o seu caso): "Talvez uma análise da diferença de culturas possa contribuir para explicar o que estou a passar. Gostaria que as pessoas soubessem que não são sempre os imigrantes a tirar vantagem das situações. Podemos tornar-nos objecto de muitos preconceitos e perseguições quase paranóicas, como acho que é o meu caso." ${ }^{14}$ Esperanza encontrava-se em pleno processo de divórcio litigioso, acusada pelo seu marido de ter casado para obter a nacionalidade portuguesa.

De um ponto de vista sociopolítico, o trabalho biográfico com migrantes traduz-se numa capacitação que podemos incluir nas medidas de empowerment humano. Este termo cobre um vasto campo de significados e disciplinas que vão da filosofia e psicologia à indústria de auto-ajuda. No domínio $\mathrm{da}$ acção social, consiste em dar às pessoas o poder, a liberdade e a informação que lhes permitem tomar decisões e participar activamente na colectividade. Os princípios do empowerment assentam na responsabilização e confiança dos actores sociais; na motivação pelo reconhecimento da acção/desempenho; no desenvolvimento contínuo de capacidades e aptidões; na promoção da liderança de todos. (Ensaios CAIS, 2008)

A capacitação dá poder aos excluídos, competência aos desmunidos, motivação para a participação. Capacitar para participar significa reconhecer todos como indispensáveis prevenindo a exclusão. Quando esta última já está instalada, como no caso de muitos migrantes, capacitar implica "praticar-se si mesmo" no horizonte de uma existência digna e exercício de plena cidadania.

$\mathrm{Na}$ medida em que as práticas de biografização podem surtir este efeito de empowerment, devem ser desenvolvidas, aperfeiçoadas e aplicadas no âmbito de uma estreita colaboração entre universitários e associações no terreno. Elas são pois aqui entendidas como lugares de produção histórica de um saber que, para além de poder, é também feito de solidariedades.

$\overline{14}$ Email, Fevereiro de 2007. 


\section{Conclusão}

Neste artigo procurámos apresentar um dispositivo emancipatório dos migrantes assente em práticas de biografização. Para tal, procedemos a uma breve definição do conceito de emancipação e contextualização científica das práticas emancipatórias. A reflexão proposta partiu da nossa experiência de trabalho junto de migrantes de origens diversas em diferentes contextos geográficos, que aceitaram contar-nos a sua história. O efeito emancipador das narrações auto-biográficas produzidas é aqui balizado pela corrente teórica das "histórias de vida em formação" e por uma metodologia dialógica que reconhece os interlocutores como co-construtores de um saber útil à comunidade.

$\mathrm{Na}$ análise dos efeitos emancipatórios da biografização pomos em relevo o seu poder libertador e estruturante: contar a sua vida é mais do que reviver o passado, é também e sobretudo o ponto de partida para organizar o presente e planear o futuro despindo a pele de antigas identidades e opressões.

Em razão de tais efeitos, esta abordagem apresenta uma relevância ética e sociopolítica capaz de aproximar os sujeitos de si próprios, de construir pontes na diversidade, inventar o diálogo intercultural e de contribuir para a participação cívica de todos.

Tal relevância põe em evidência o papel das ciências sociais na criação de dispositivos de reflexão-acção contributivos para o diálogo intercultural. Este não é apanágio das plataformas de análise dos investigadores. É também osso do ofício do trabalho de investigação. Nesse sentido julgamos poder contribuir com o presente texto sugerindo uma aproximação entre pesquisadores e migrantes no terreno através da abordagem biográfica.

\section{Referências bibliográficas}

Beneduce, Roberto (2009), "Etnopsiquiatria e migração: a produção histórica e cultural do sofrimento", in Elsa Lechner (org.), Migração, saúde e diversidade cultural. Lisboa: ICS.

Caruth, Cathy (1996), Unclaimed Experience: Trauma, Narrative and History. Baltimore: John Hopkins Press.

Cravo, António (2000), "No equilíbrio do vai e vem. Dossier autobiográfico”. Paris: não editado.

Delory-Momberger, Christine (2004), Les histoires de vie: De l'invention de soi au projet de formation. Paris: Anthropos. 2e éd.

Delory-Momberger, Christine (2006), "Les ateliers biographiques de projet", in Educação e Pesquisa, 32(2). São Paulo.

Ensaios CAIS (2008), Empowerment: capacitar para participar. Lisboa: Padrões Culturais. 
Freire, Paulo (1963), Alfabetização e conscientização, Porto Alegre: Editora Emma.

Freire, Paulo (1967), Educação como prática da liberdade, Rio de Janeiro: Paz e Terra.

Freire, Paulo (1969), Pedagogia do oprimido. Rio de Janeiro: Paz e Terra.

Garibay, Françoise; Séguier, Michel (2009), Pratiques émancipatrices: actualités de Paulo Freire. Paris: Éditions Syllepse.

Lechner, Elsa (2003), "Enfants de l'eau: la reconstruction de l'identité en situation d'émigration. Le cas des Transmontanos en région parisienne", Tese de Doutoramento, EHESS, Paris.

Lechner, Elsa (2007), “Diálogos de vida: a pesquisa biográfica no estudo da imigração”. Comunicação apresentada no Simpósio Internacional Histórias de vida: novos desafios teóricos e práticos. ISCTE, Lisboa, 12 de Junho.

Lechner, Elsa (org.) (2009), Migração, saúde e diversidade cultural. Lisboa : ICS.

Pineau, Gaston (1996), "Les histoires de vie comme art formateur de l'existence", in Pratiques de formation, 31, 65-80.

Pineau, Gaston (2006), "As histórias de vida como artes formadoras da existência”, in Elizeu Souza e Maria Helena Abrahão (org.), Tempos, narrativas e ficções: a invenção de si. Porto Alegre: Edipucrs.

Plummer, Kenneth (2003), "Intimate citizenship and the culture of sexual story telling", in Jeffrey Weeks, Janet Holland, Matthew Waites (org.) Sexualites and Society. A Reader. Cambridge : Polity Press.

Pollner, Melvin (1996), "Narrative mapping of social worlds", in Symbolic Interaction, 19(3): 203-223.

Sousa Santos, Boaventura (org.) (2003), Reconbecer para libertar: os caminhos do cosmopolitismo multicultural. Reinventar a emancipação social, 3. Rio de Janeiro: Civilização Brasileira.

Sousa Santos, Boaventura. (org.) (2008), As vozes do mundo. Reinventar a emancipação social, 6. Porto: Afrontamento.

Vidricaire, André (2009), "Production collective d'un savoir émancipateur, D-Trois-Pierres (Montréal, Canada)” in Françoise Garibay et Michel Séguier (org.), Pratiques émancipatrices: actualités de Paulo Freire. Paris: Syllepse. 